American J. of Engineering and Applied Sciences 3 (4): 740-748, 2010

ISSN 1941-7020

(C) 2010 Science Publications

\title{
Effect of Cycle Duration and Phasing on Thermomechanical Fatigue of Dog-Bone Specimens Made form Steel
}

\author{
${ }^{1}$ Achegaf Zineb, ${ }^{1}$ Khamlichi Abdellatif and ${ }^{2}$ Francisco Mata Cabrera \\ ${ }^{1}$ Modeling and Simulation of Mechanical Systems Laboratory, \\ Faculty of Sciences at Tetouan 93002, BP. 2121, M'hannech, Tetouan, Morocco \\ ${ }^{2}$ Department of Mechanical Engineering, Polytechnic School of Almaden, \\ 1 Square Manuel Meca, 13400 Almaden, Ciudad Real, Spain
}

\begin{abstract}
Problem statement: Lifetime of standard dog-bone specimens made form steel as affected by phasing between thermal cycles and strains cycles and by cycle duration in thermomechanical fatigue is assessed under various conditions of loading. Approach: The methodology used was based on finite element post-processing analysis by specialized fatigue software package that takes into account coupling of damage from three primary sources: Fatigue, oxidation and creep. Results: A parametric study has been conducted for various thermomechanical loadings and effects of phasing and cycle duration on lifetime have been evaluated. The associated percentages of damage mechanisms due to fatigue, oxidation and creep have been determined. Conclusion: It has been shown that both phasing and cycle duration have considerable effect on lifetime. In the range of parameters investigated, the in-phase cycles were found to reduce considerably damage in the specimen for low pressures and low temperatures. The results have shown also that there was no way of unique comparison of the various phasing configurations, since there exists always a case of thermomechanical loading for which one phasing configuration yields higher damage than any another configuration.
\end{abstract}

Key words: Fatigue, thermomechanical loading, phasing configuration, in-phase cycles, out-of-phase cycles, finite element method, isothermal, mechanical fatigue, dog-bone specimen, plasticity, thermal cycles

\section{INTRODUCTION}

Mechanical properties of materials are temperature dependent. In general, material performances decrease with increasing temperature, but this is not always the case because Young's modulus of some tempered steels increases slightly at mid temperatures before decreasing at high temperatures. The effect of high temperature on mechanical properties is linked to transformations occurring at the material microstructure level under various physical processes. In general, inelastic deformations occur more easily at elevated temperatures yielding that more plastic deformation and creep can develop in the plastic zone near a fatigue crack tip. Fatigue resistance is also affected by temperature and by oxidation process which may be activated. Fatigue damage accumulation is expected then to be very affected by temperature increase. All these characteristics constitute the mean features of what it is termed Thermomechanical Fatigue (TMF).
The combined action of cyclic strains at high temperatures with time-dependent temperature variations applies in practice to specific components that are exposed during their service to high temperatures and to oscillating mechanical loads. In general, the temperature profile varies between a high operating temperature and a low temperature. Cyclic thermal stresses can develop then if the structure is constrained against free expansion. This yields to considerable complexity of the fatigue problem scenario as temperature and time become two additional variables.

Discarding situations where temperature transients are significant, temperature can be assumed at each instant to be uniform over the whole domain and only concurrent static thermal cycles and static strain cycles could be assumed to occur.

Thermomechanical Fatigue (TMF) is characterised by strong interaction between mechanical fatigue, creep and oxidation which leads to complex damage

Corresponding Author: Khamlichi Abdellatif, Modeling and Simulation of Mechanical Systems Laboratory, Faculty of Sciences at Tetouan 93002, BP. 2121, M'hannech, Tetouan, Morocco, Tel: +212 667795068 Fax: +212539994500 
mechanisms, (Rahman et al., 2009a; Zhuang and Swansson, 1998). Thomas et al. (1982) had shown through experiments that TMF testing is more severe than isothermal testing conducted at the maximum temperature. Bill et al. (1984) had found that lifetime of material specimens under in-phase thermomechanical cycling is well below isothermal creep-fatigue lives obtained at various fixed temperatures belonging to the temperature range that had been investigated. Fatigue damage is dependent on the phase relationship between strain and temperature. There are two extreme thermomechanical situations that have been generally considered; In-Phase (IP) and out-Of-Phase (OP) cycles. In general, both in-phase and out-of-phase stress and temperature cycles were found to be more damaging than isothermal stress cycles. Often, but not at all times, in-phase stress cycles and temperature cycles were found to be more damaging than out-ofphase cycles. The phasing effect was also found to be material dependent. In the special case of metal matrix composites undergoing low cycle fatigue, this phase effect was discussed in (Halford et al., 1976).

The fatigue damage process is driven by cyclic plastic strains where oxidation and creep effects could be neglected. Fatigue damage is dominant at high strain ranges, strain rates and low temperatures.

Creep damage result essentially from a microscopic diffusion process. Maximum stress has a dominant role in this fatigue mechanism and the interaction of the strain rate and temperature was recognized to have a strong influence on it, (Sehitoglu and Boismier, 1990; Sehitoglu, 1992; Djavanroodi, 2008).

Oxidation damage can occur at the surface material. This process occurs more spontaneously at higher temperatures according to two major mechanisms, (Sehitoglu and Boismier, 1990; Sehitoglu, 1992; Abdullah et al., 2009). In the first case, the oxide layer forms when the surface is hot and in compression. The oxide layer becomes brittle at the lower temperature and during mechanical straining it cracks to expose new clean metal surfaces which will rapidly oxidize. In the second case, the oxide forms during the hot portion of the loading cycle while the material undergoes tension. Cooling after that will cause delamination and fracture of the oxide and new clean metal surfaces are then exposed. Oxidation during TMF is an important factor while it is hardly perceptible in isothermal loading as various tests had demonstrated this fact.

Both creep diffusion and oxidation is highly temperature and time dependant. In particular cycle duration is of crucial importance in these fatigue mechanisms, (Sehitoglu and Boismier, 1990; Sehitoglu, 1992).

A large number of thermomechanical fatigue models were proposed in the literature for the prediction of TMF lifetime, (Zhuang and Swansson, 1998). Each model was derived however for a particular use of a given material under specific ranges of temperature and cyclic strain. No versatile model can nowadays be used to predict lifetime under arbitrary thermomechanical loading conditions.

In this work, fatigue damage resulting from various thermomechanical loadings acting on the structure of a standard dog-bone specimen is investigated. This specimen is used habitually to investigate experimentally TMF (Lawson et al., 1991; Velay et al., 2006). The special effects of phasing between strain cycles and thermal cycles and that of cycle duration are assessed. Finite element modeling of the part is performed at first, the most loaded node is identified after that, then the specialized fatigue post-processing software package, e-fatigue, is used to calculate lifetime under any considered combination of thermal cycles, strain cycles and cycle durations according to the strain accumulation based Sehitoglu model (Neu and Sehitoglu, 1989; Sehitoglu and Boismier, 1990; Sehitoglu, 1992).

\section{MATERIALS AND METHODS}

Different approaches have been introduced for the prediction of fatigue lifetime (Swanson et al., 1986; Rahman et al., 2009b; Abdullah et al., 2009; Gocmez et al., 2010). There are phenomenological models which relate measured total mechanical fields and lifetime without considering explicitly the different damaging mechanisms, (Gao et al., 2005; 2007). In this kind of approaches considerable experimental data is usually needed to identify the model parameters. To reduce the experimental effort to a strict minimum, rational approaches to modeling fatigue lifetime were considered. These include three families: damage partitioning based methods, crack growth based models and fatigue theories based on energetic approaches. In all these approaches model parameters are identified from specific tests.

In cumulative damage based models, explicit consideration of the different damaging mechanisms is carried out, (Halford et al., 1976; 1988; Rees and Dyson, 1986; Neu and Sehitoglu, 1989; Sehitoglu, 1990; Lemaitre and Chaboche, 1990; Sehitoglu, 1992; Kang et al., 2007). In crack growth based models, life is related to local inelastic strains at the crack tip (Newman, 1984; Christ et al., 2003; Djavanroodi, 2008). In 
energetic based fatigue theories, a relation between dissipated energy and the number of cycles to failure is assessed (Skelton, 1991; 1993).

From a practical point of view, damage strain partitioning based methods were recognized to be pertinent if one decides to estimate fatigue lifetime by performing finite element post-processing, (DeAndres et al., 1999; Gaiera and Dannbauera, 2003; Kocabicak and Firat, 2004; Lei, 2008; Sun and Shang, 2010). Strain damage partitioning method will be used in the following to perform prediction of TMF lifetime (Boismier and Sehitoglu, 1990; Sehitoglu and Boismier, 1990; Sehitoglu, 1992) by means of finite element postprocessing.

There are many active mechanisms in the TMF process. But, it is convenient to consider damage to result from three major sources: fatigue, oxidation and creep. Damage from each process is summed to obtain an estimate of the total fatigue life, $\mathrm{N}_{\mathrm{f}}$, according to the following equation, (Neu and Sehitoglu, 1989a; 1989b):

$$
\frac{1}{N_{f}}=\frac{1}{N_{f}^{m}}+\frac{1}{N_{f}^{o x}}+\frac{1}{N_{f}^{c r}}
$$

Where:

$$
\begin{aligned}
\mathrm{N}_{\mathrm{f}}^{\mathrm{m}}= & \text { The fatigue damage lifetime, } \mathrm{N}_{\mathrm{f}}^{\mathrm{ox}} \text { the oxidation } \\
& \text { lifetime } \\
\mathrm{N}_{\mathrm{f}}^{\mathrm{cr}}= & \text { The creep lifetime }
\end{aligned}
$$

The strain-life equation is the most common description mode of the fatigue damage process. This equation writes

$$
\frac{\Delta \varepsilon}{2}=\frac{\sigma_{f}^{\prime}}{E}\left(2 N_{f}^{m}\right)^{b}+\varepsilon_{f}^{\prime}\left(2 N_{f}^{m}\right)^{c}
$$

Where:

$\sigma_{\mathrm{f}}^{\prime}=$ The fatigue strength coefficient

$\mathrm{b}=$ The Basquin's fatigue strength exponent

$\varepsilon_{\mathrm{f}}^{\prime}=$ The fatigue ductility coefficient, $\mathrm{c}$ the CoffinManson fatigue ductility exponent

$\mathrm{E}=$ The Young's modulus

A linear temperature dependence for the elastic modulus is frequently employed:

$$
\mathrm{E}=\mathrm{E}_{0}-\mathrm{E}_{1} \mathrm{~T}
$$

Where:

$\mathrm{E}_{0}=$ The elastic modulus

$\mathrm{E}_{1}=$ The elastic modulus temperature dependence
The oxidation damage formulation due to (Neu and Sehitoglu, 1989a; 1989b) predicts that oxide damage will occur when the strain range exceeds a threshold $\Delta \varepsilon_{\text {mech }}>\varepsilon_{0}$ for oxide cracking. Oxidation damage equation is given by:

$\frac{1}{\mathrm{~N}_{\mathrm{f}}^{\mathrm{ox}}}=\left(\frac{\mathrm{H}_{\mathrm{cr}}}{\Phi_{\mathrm{ox}} \mathrm{K}_{\text {peff }}}\right)^{-\frac{1}{\beta}} \frac{2\left(\Delta \varepsilon_{\text {mech }}\right)^{\frac{2}{\beta}+1}}{\dot{\varepsilon}^{1-\frac{\lambda}{\beta}}}$

With:

$$
\begin{aligned}
& \Phi_{\text {ox }}=\frac{1}{\mathrm{t}_{\mathrm{c}}} \int_{0}^{\mathrm{t}_{\mathrm{c}}} \exp \left(-\frac{1}{2}\left(\frac{\dot{\varepsilon}_{\text {th }} / \dot{\varepsilon}_{\text {mech }}+1}{\xi_{\text {ox }}}\right)^{2}\right) \mathrm{dt}, \\
& \mathrm{K}_{\text {peff }}=\int_{0}^{\mathrm{t}_{\mathrm{c}}} \mathrm{D}_{0} \mathrm{e}^{-\frac{\Delta \mathrm{H}_{\text {ox }}}{\mathrm{RT}}} \mathrm{dt}
\end{aligned}
$$

Where:

$\varepsilon_{0} \quad=$ The threshold strain for oxide cracking

$\mathrm{t}_{\mathrm{c}} \quad=$ The cycle duration

$\mathrm{H}_{\mathrm{cr}}=\mathrm{A}$ constant related to critical oxide thickness

$\beta=$ The mechanical strain range exponent

$\lambda=$ The thermal strain rate sensitivity exponent

$\xi_{0 \mathrm{x}}=$ The oxidation phasing constant for thermal and mechanical strains

$\Delta \mathrm{H}_{0 \mathrm{x}}=$ The activation energy for oxidation

$\mathrm{K}_{\text {peff }}=$ The effective parabolic oxidation constant

$\mathrm{D}_{0} \quad=$ A scaling constant for oxidation

The phasing factor $\xi_{0 \mathrm{x}}$ is introduced to account for the type of oxide cracking that can occur in either IP or OP loading. Phasing is represented by the ratio of thermal and mechanical strain rates $\dot{\varepsilon}_{\mathrm{th}} / \dot{\varepsilon}_{\text {mech }}$. From laboratory tests the OP-TMF $\left(\dot{\varepsilon}_{\mathrm{th}} / \dot{\varepsilon}_{\text {mech }}=-1\right)$ showed the most oxidation damage, $\Phi_{\text {ox }}=1$, while for the free expansion case $\dot{\varepsilon}_{\mathrm{th}} / \dot{\varepsilon}_{\text {mech }}= \pm \infty$ no oxidation damage was observed, $\Phi_{\text {ox }}=0$.

The creep formulation suggested by (Neu and Sehitoglu, 1989a; 1989b) predicts damage according to the equation:

$$
\frac{1}{\mathrm{~N}_{\mathrm{f}}^{\mathrm{cr}}}=\int_{0}^{\mathrm{t}_{\mathrm{c}}} \mathrm{A}_{\mathrm{cr}} \Phi_{\mathrm{cr}} \mathrm{e}^{-\frac{\Delta \mathrm{H}_{\mathrm{cr}}}{\mathrm{RT}}}\left(\frac{\alpha_{1} \bar{\sigma}+\alpha_{2} \sigma_{\mathrm{m}}}{\mathrm{K}}\right)^{\mathrm{m}} \mathrm{dt}
$$

With:

$$
\Phi_{\mathrm{cr}}=\frac{1}{\mathrm{t}_{\mathrm{c}}} \int_{0}^{\mathrm{t}_{\mathrm{c}}} \exp \left(-\frac{1}{2}\left(\frac{\dot{\varepsilon}_{\mathrm{th}} / \dot{\varepsilon}_{\text {mech }}-1}{\xi_{\mathrm{cr}}}\right)^{2}\right) \mathrm{dt}
$$




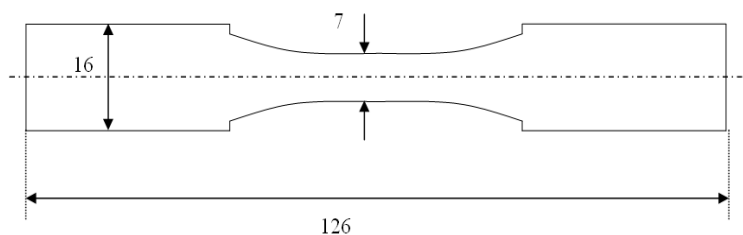

Fig. 1: Geometric configuration of the considered specimen

Where:

$\Delta H_{\text {cr }}=$ The activation energy for creep

$\mathrm{A}_{\mathrm{cr}}=$ A scaling constant for creep

$\mathrm{m}=$ The creep stress exponent

$\bar{\sigma}=$ The equivalent stress $\left(\bar{\sigma}=(2 / 3) S_{i j} S_{i j}\right.$ with $S_{i j}$ the deviatoric stresses)

$\sigma_{\mathrm{m}}=$ The hydrostatic stress $\left(\sigma_{\mathrm{m}}=\sigma_{\mathrm{ii}} / 3\right)$

$\alpha_{1}=$ A stress state constant

$\alpha_{2}=$ A hydrostatic stress sensitivity constant

$\xi_{\text {cr }}=$ The creep phasing constant for thermal and mechanical strains

$\mathrm{m}=$ A material constant

$\mathrm{K}=$ The drag stress

The drag stress is an internal state variable that is related to the strength of the material. It is the stress that defines the transition from creep to plasticity dominated deformation. It is not constant but depends on the temperature, T. A linear temperature for the drag stress is often employed:

$$
\mathrm{K}=\mathrm{K}_{0}-\mathrm{K}_{1} \mathrm{~T}
$$

Where:

$\mathrm{K}_{0}=$ The back stress

$\mathrm{K}_{1}=$ The back stress temperature dependence

If no creep damage occurs in compression $\alpha_{1}=1 / 3$ and $\alpha_{2}=1$. From laboratory tests the IP-TMF $\left(\dot{\varepsilon}_{\mathrm{th}} / \dot{\varepsilon}_{\text {mech }}=1\right)$ showed the most creep damage, $\Phi_{\mathrm{cr}}=1$.

The following methodology is used to derive a numerical modeling of TMF. At first, finite element modeling of the dog-bone specimen under specific applied mechanical loading cycles and temperature cycles is performed. The most strained mesh point is identified. Total strains histories in that point are then extracted. These constitutes with the cycle duration and the material TMF data inputs of the eFatigue system (https://efatigue.com/) which is used for evaluating fatigue life through using the High Temperature Fatigue Calculator.

The standard dog-bone specimen is axisymmetric with length $\mathrm{L}=126 \times 10^{-3} \mathrm{~m}$ and variable radius between $R_{\min }=7 \times 10^{-3} \mathrm{~m}$ and $R_{\max }=16 \times 10^{-3} \mathrm{~m}$. Only the quarter of a meridian section of this specimen needs to be modeled. Finite element modeling is performed by assuming 2-D axisymmetric deformation.

Elastic or Elastic plastic strain cycles and thermal cycles are considered to act simultaneously on the specimen. The mechanical loading results from applying a tension pressure designated by $\mathrm{P}$ at the outside extremity of the specimen. To obtain a thermal stress loading under homogeneous uniform temperature distribution, the specimen was restrained against axial expansion by creating an interaction boundary condition at its outside edge (Fig. 1).

The material properties used are those of the SAE 1070 steel. This steel is considered in the temperature range 20 and $600^{\circ} \mathrm{C}$.

The stresses are computed by using the constitutive model suggested by (Bodner et al., 1979). In this model, the combined effects of creep and plasticity are treated as inelastic strains. At lower stresses $\bar{\sigma} \leq \mathrm{K}_{0}$, where $\bar{\sigma}$ is the equivalent stress and $\mathrm{K}_{0}$ a drag stress, time dependant creep dominates the behavior. Plasticity dominates at higher stresses when $\bar{\sigma} \geq \mathrm{K}_{0}$. The drag stress is an internal state variable that is related to the strength of the material. It is the stress that defines the transition from creep to plasticity dominated deformation and depends on the temperature.

The Bodner et al. (1979) constitutive model writes:

$$
\dot{\varepsilon}_{\text {mech }}=\frac{\dot{\bar{\sigma}}}{\mathrm{E}}+\mathrm{A}_{0}\left(\frac{\bar{\sigma}}{\mathrm{K}}\right)^{\mathrm{n}_{1}} \exp \left(-\frac{\Delta \mathrm{H}^{\text {in }}}{\mathrm{RT}}\right) \text { if } \bar{\sigma} \leq \mathrm{K}
$$

Where:

$\Delta \mathrm{H}^{\text {in }}=$ The activation energy for inelastic deformation

$\mathrm{A}_{0} \quad=$ Scaling constant

$\mathrm{n}_{1} \quad=$ Exponent for creep dominated deformation

$\mathrm{n}_{2}=$ Exponent for plasticity dominated deformation

The thermal expansion coefficient $\alpha$ is also needed in the analysis to determine thermal strains.

Poisson's coefficient does not depend on temperature and takes the constant value $v=0.3$.

These TMF equations represent a model for steady state deformation and require a total of 27 material modeling constants. For the SAE 1070 steel Fatigue Calculator provides fatigue material characteristics as a default option. Using the units: $\mathrm{MPa}$ for $\mathrm{E}, \sigma_{\mathrm{f}}^{\prime}$ and $\mathrm{K}_{0}$ and ${ }^{\circ} \mathrm{C}$ for temperature $\mathrm{T}$, the following parameters were used during eFatigue simulations:

$\alpha=1.18 \times 10^{-5} ; \mathrm{E}(\mathrm{T})=211000+35 \mathrm{~T}$ if $\mathrm{T} \leq 435^{\circ} \mathrm{C} ; \mathrm{E}(\mathrm{T})=$ $318100-283 \mathrm{~T}$ if $\mathrm{T}>435^{\circ} \mathrm{C} ; \mathrm{v}=0.3 ; \mathrm{K}_{0}=256+0.0014 \mathrm{~T}^{2}$ 
if $\mathrm{T}<304^{\circ} \mathrm{C} ; \mathrm{K}=568-0.6 \mathrm{~T}$ if $\mathrm{T} \geq 304^{\circ} \mathrm{C} ; \mathrm{n}_{1}=5.4 ; \mathrm{n}_{2}=$ $8.3 ; \mathrm{A}_{0}=4 \times 10^{9} ; \Delta \mathrm{H}_{\mathrm{in}}=210600 ; \mathrm{E}=201510 ; \sigma_{\mathrm{f}}^{\prime}=958$; $\mathrm{b}=-0.093 ; \varepsilon_{\mathrm{f}}^{\prime}=0.0996 ; \mathrm{c}=-0.464 ; \xi_{\mathrm{cr}}=0.4 ; \Delta \mathrm{H}_{\mathrm{cr}}=$ $248100 ; \mathrm{A}_{\mathrm{cr}}=1.562 \times 10^{14} ; \mathrm{m}=11.34 ; \alpha_{1}=0.333 ; \alpha_{2}=$ $1 ; \xi_{0 \mathrm{x}}=2 ; \lambda=0.75 ; \beta=1.5 ; \mathrm{D}_{0}=6.95 \times 10^{7} ; \Delta \mathrm{H}_{0 \mathrm{x}} ; \mathrm{H}_{\mathrm{cr}}=$ $1.536 \times 10^{-2} ; \varepsilon_{0}=0$.

The thermomecanical loading was applied according to the phasing configurations shown in Fig. 2-5. The phasing is defined as the advance of temperature cycles with respect to strain cycles.

Five different types of analyses were performed under Abaqus software:

- Isothermal mechanical loading containing one strain cycle and temperature is constant (Iso), Fig. 2

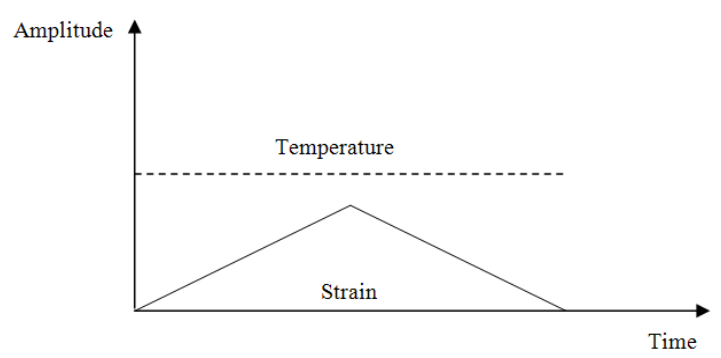

Fig. 2: Isothermal cyclic loading

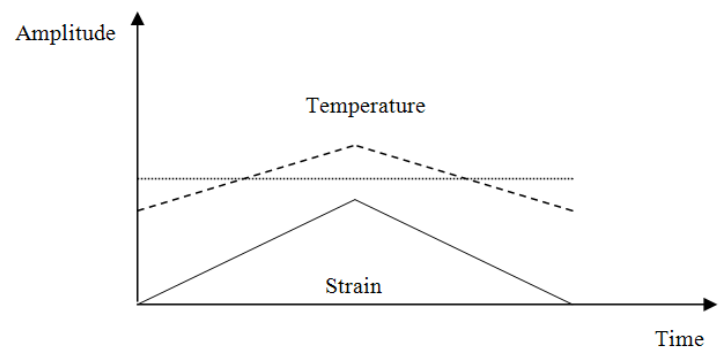

Fig. 3: Thermomechanical in-phase cyclic loading

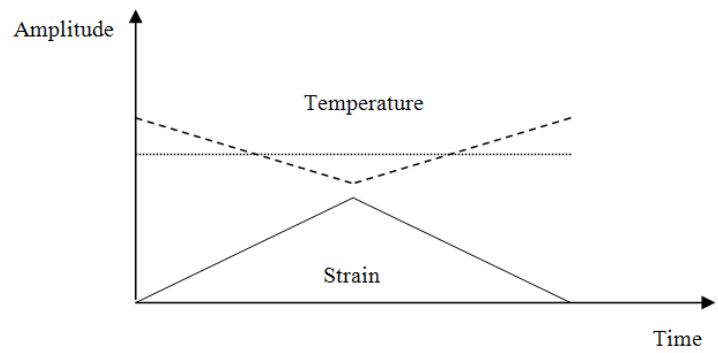

Fig. 4: Thermomechanical out-of-phase cyclic loading
- Thermomechanical loading containing one strain cycle and one thermal cycle with temperature in phase with strain (IP-TMF), Fig. 3

- Thermomechanical loading containing one strain cycle and one thermal cycle with temperature out of phase with strain (OP-TMF), Fig. 4

- Nonproportional thermomechanical loading containing one strain cycle and one thermal cycle with temperature in advance of a quarter of period (A-TMF), Fig. 5

- Nonproportional thermomechanical loading containing one strain cycle and one thermal cycle with temperature in delay of a quarter of period (DTMF), Fig. 6

Mesh refinement is one of the most important issues in the finite element simulation of fatigue stress concentration. Here, an adaptive remeshing technique was used. Beginning with a coarse mesh, Fig. 7, the initial mesh was refined to satisfy the asymptotic convergence condition. Figure 8 shows the refined mesh for a particular case of TMF loading.

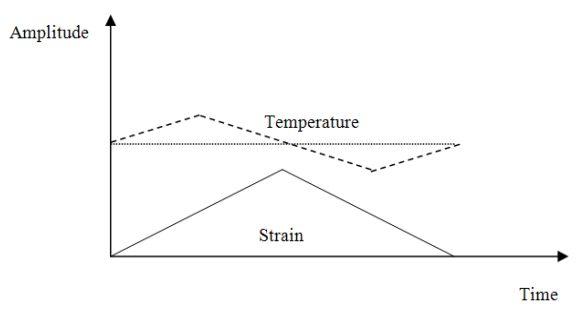

Fig. 5: Nonproportional thermomechanical cyclic loading with a quarter of period advance

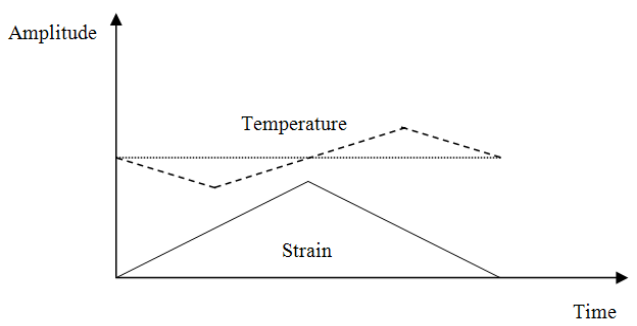

Fig. 6: Nonproportional thermomechanical cyclic loading with a quarter of period delay

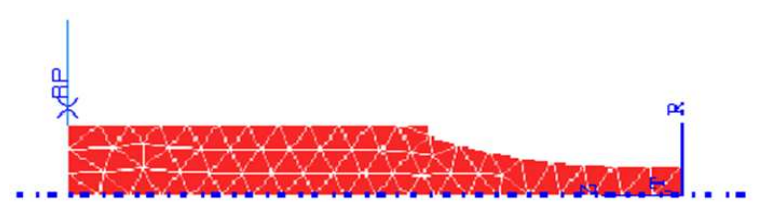

Fig. 7: Initial coarse mesh of the modeled portion of the specimen 


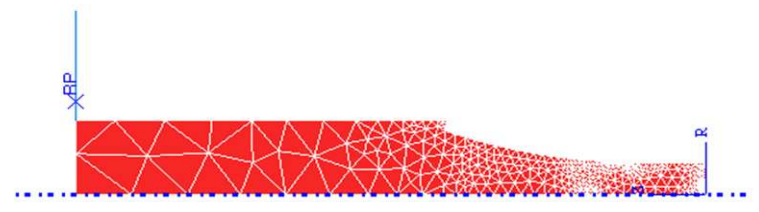

Fig. 8: Refined mesh of the modelled portion of the specimen

Abaqus finite element results are analysed and the most strained point is determined. The total strain history at this point is extracted and transferred after that as input to the fatigue post-processing software Fatigue Calculator. In addition to strain cycles, user can define temperature cycles to be considered in TMF lifetime prediction. But, since the original TMF theory of Sehitoglu as formulated by Eq. 1-4 is onedimensional and the dog-bone specimen is subjected to axisymmetric loadings, three-dimensional TMF model is needed. This is achieved by extending the onedimensional theory to a three-dimensional state of stress using the concept of critical plane, (Affeldt et al., 2003). The maximum shear strain is then used instead of the one-dimensional strain according to:

$\frac{\Delta \gamma_{\text {mech }}}{2}=\frac{\left(1+v_{e}\right) \sigma_{f}^{\prime}}{E}\left(2 N_{f}^{m}\right)^{b}+\left(1+v_{p}\right) \varepsilon_{f}^{\prime}\left(2 N_{f}^{m}\right)^{c}$

Where:

$\gamma_{\text {mech }}=$ The maximum mechanical shear strain on the critical shear plane

$v_{\mathrm{e}}$ and $v_{\mathrm{p}}=$ The Poisson's ratios for respectively elastic and plastic deformation work.

The values $v_{\mathrm{e}}=0.25$ and $v_{\mathrm{p}}=0.5$ are used in this

\section{RESULTS}

A parametric study was conducted on a dog-bone specimen having the material data specified here above under the following conditions:

- Two values of the pressure were applied: $\mathrm{P} 1=360$ $\mathrm{MPa}$ and $\mathrm{P} 2=560 \mathrm{MPa}$

- For the isothermal case, the reference temperature was varied in the set $\{200 ; 400 ; 600\}\left({ }^{\circ} \mathrm{C}\right)$

- For the thermomechanical fatigue cases, the temperature range values were varied in the set $\{[200,400] ;[200,600]\}\left({ }^{\circ} \mathrm{C}\right)$

- Three values of cycle duration were applied: $\Delta \mathrm{t} 1=$ $30 \mathrm{sec} ; \Delta \mathrm{t} 2=120 \mathrm{sec}$ and $\Delta \mathrm{t} 3=210 \mathrm{sec}$

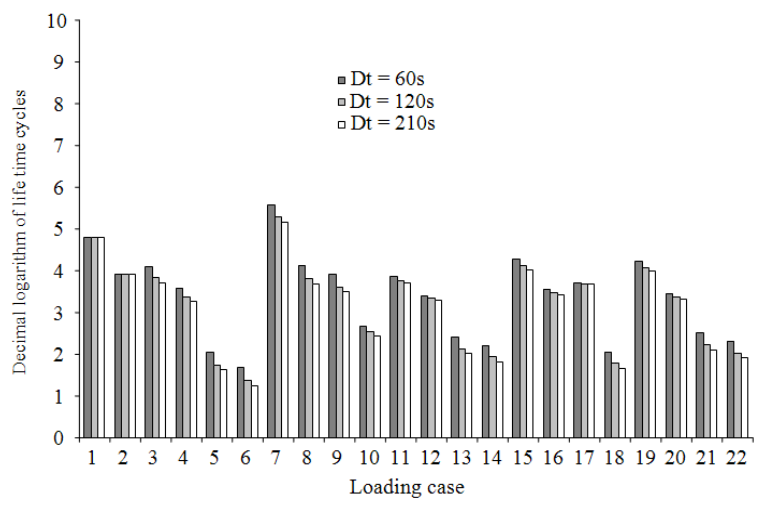

Fig. 9: Decimal logarithm of cumulated fatigue lifetime cycles as function of the loading case and cycle duration

Table 1: Loading case numbering as function of applied pressure, temperature range and phasing

\begin{tabular}{llll}
\hline $\begin{array}{l}\text { Loading case } \\
\text { number }\end{array}$ & $\begin{array}{l}\text { Pressure } \\
(\mathrm{MPa})\end{array}$ & $\begin{array}{l}\text { Temperature } \\
\text { range }\left({ }^{\circ} \mathrm{C}\right)\end{array}$ & $\begin{array}{l}\text { Phasing } \\
\text { duration }\end{array}$ \\
\hline 1 & 360 & 200 & Isothermal \\
2 & 560 & 200 & Isothermal \\
3 & 360 & 400 & Isothermal \\
4 & 560 & 400 & Isothermal \\
5 & 360 & 600 & Isothermal \\
6 & 560 & 600 & Isothermal \\
7 & 360 & $200-400$ & IP-TMF \\
8 & 560 & $200-400$ & IP-TMF \\
9 & 360 & $200-600$ & IP-TMF \\
10 & 560 & $200-600$ & IP-TMF \\
11 & 360 & $200-400$ & OP-TMF \\
12 & 560 & $200-400$ & OP-TMF \\
13 & 360 & $200-600$ & OP-TMF \\
14 & 560 & $200-600$ & OP-TMF \\
15 & 360 & $200-400$ & A-TMF \\
16 & 560 & $200-400$ & A-TMF \\
17 & 360 & $200-600$ & A-TMF \\
18 & 560 & $200-600$ & A-TMF \\
19 & 360 & $200-400$ & D-TMF \\
20 & 560 & $200-400$ & D-TMF \\
21 & 360 & $200-600$ & D-TMF \\
22 & 560 & $200-600$ & D-TMF \\
\hline
\end{tabular}

Pressure P1 was chosen to yield only elastic deformations in the whole dog-bone specimen when subject to isothermal loading, while pressure P2 is chosen to yield plastic deformations in the central zone of the specimen.

Table 1 summarizes all the combinations for isothermal and TMF fatigue analyses performed in the following.

Using the finite element software Abaqus, the dogbone specimen was modelled and the most loaded point identified. Strains either resulting from the applied pressure or from the temperature gradient were computed at that point. Fatigue computation for each case was then performed by means of eFatigue software. 
Figure 9 gives the obtained cumulated fatigue results in terms of the decimal logarithm of lifetime cycles for all the isothermal and TMF and cycle duration cases.

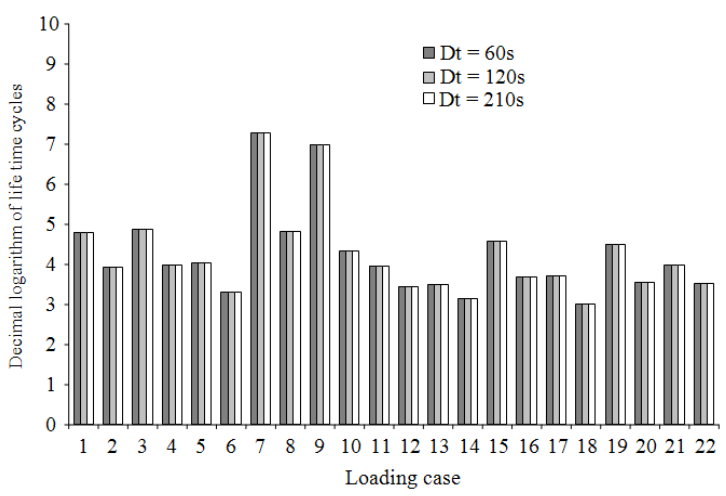

Fig. 10: Decimal logarithm of fatigue lifetime cycles as function of the loading case and cycle duration

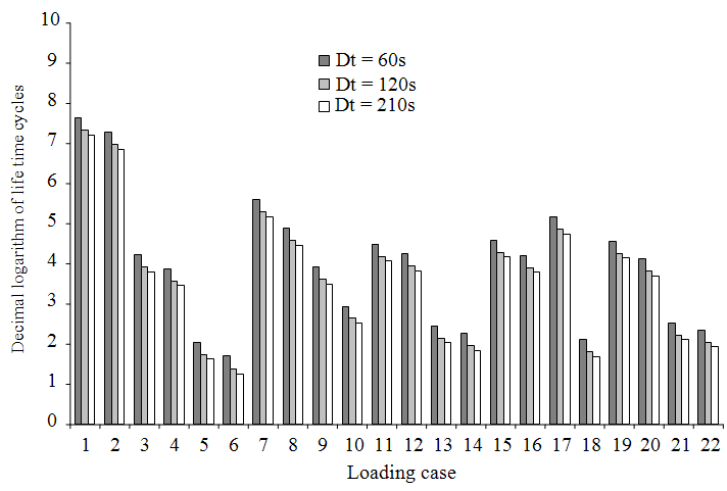

Fig. 11: Decimal logarithm of oxidation fatigue lifetime cycles as function of the loading case and cycle duration

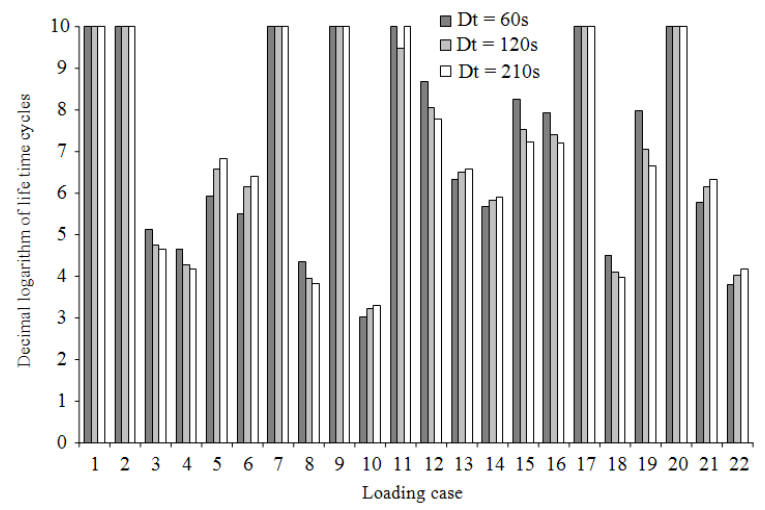

Fig. 12: Decimal logarithm of creep fatigue lifetime cycles as function of the loading case and cycle duration
Figure 10 gives the obtained fatigue results in terms of the decimal logarithm of fatigue lifetime cycles for all the isothermal and TMF and cycle duration cases.

Figure 11 gives the obtained fatigue results in terms of the decimal logarithm of oxidation fatigue lifetime cycles for all the isothermal and TMF and cycle duration cases.

Figure 12 gives the obtained fatigue results in terms of the decimal logarithm of creep fatigue lifetime cycles for all the isothermal and TMF cases and cycle durations.

\section{DISCUSSION}

A general remark is that increasing the cycle time yields decrease of the lifetime cycles for all cases where oxidation and creep are significant. Except for the two first loading cases for which temperature is low, all the others loadings show sensitivity to cycle time.

By comparing the load case 6 with the cases 10 , 14, 18 and 22, Fig. 9 shows that the isothermal loading can be more damaging than themomechanical loading, unlike what is widely quoted in literature dealing with TMF.

As shown in Fig. 9, the OP-TMF lifetimes, cases 11-14, were found to be most of the time less than the isothermal case with the same pressure and the same temperature range, but for pressure $\mathrm{P} 3$ the isothermal fatigue at $600^{\circ} \mathrm{C}$ is found to be more damaging than the OP-TMF fatigue in the temperature range 400 and $600^{\circ} \mathrm{C}$.

From Fig. 9, it can be noticed that almost all the time the OP-TMF lifetime is less than that of the IPTMF case. However for high pressures and high temperatures the difference between the In-Phase and Out-of-Phase cases decreases.

Considering now the phasing effect, Fig. 9 shows that there is no universal hierarchy as to the fatigue lifetime when comparing all the phasing configurations. There exists always at least a combination with the same pressure and temperature range data for which a phasing configuration has longer life than another and vice versa.

The last remark can also be drawn when comparing the lifetime cycles related to mechanical fatigue, oxidation or creep, as given in Fig. 10-12.

Considering damage percentages associated to the various mechanisms of fatigue, it could be noticed that in the isothermal case all the mechanisms: fatigue, oxidation and creep are present. Fatigue mechanism part dominates at lower temperatures and its effect increases with increasing pressure. Oxidation 
mechanism becomes important for temperatures exceeding $400^{\circ} \mathrm{C}$ and dominates damage for the temperature $600^{\circ} \mathrm{C}$. Creep mechanism is not significant for temperatures strictly less than $400^{\circ} \mathrm{C}$ while it becomes very critical for temperatures exceeding $400^{\circ} \mathrm{C}$.

\section{CONCLUSION}

Lifetime of a standard dog-bone specimen with special boundary conditions and subjected to the action of various thermomechanical loadings was investigated by using finite element numerical modeling in conjunction with specialized fatigue post-processing software. Numerical simulations have shown that thermomechanical fatigue is not always more damaging than isothermal fatigue. The in-phase cycles were found to reduce considerably damage in the specimen for low pressures and low temperatures in comparison with the isothermal case while out-of-phase cycles had yielded more damage than the isothermal case. The results have shown also that there is no unique comparison of the various phasing configurations, since there exists always a case for which one phasing configuration loading yields higher damage than the other configurations.

All the damaging mechanisms were recognized to be active with fatigue to dominate at high pressures and low temperatures, while oxidation and creep effects were found to increase rapidly with increasing temperature and to be strongly coupled to the phasing configuration.

\section{ACKNOWLEDGMENT}

The researchers would like to thank the Moroccan CNRST for having supported part of this research under student grant D2/001.

\section{REFERENCES}

Abdullah, S., M.F. Abdullah, A.K. Ariffin and A. Jalar, 2009. Thermal-mechanical analysis of a different leadframe thickness of semiconductor package under the reflow process. Am. J. Applied Sci., 6: 616-625. DOI: 10.3844/ajassp.2009.616.625

Abdullah, S., C.K.E. Nizwan and M.Z. Nuawi, 2009. A Study of Fatigue Data Editing using the ShortTime Fourier Transform (STFT). Am. J. Applied Sci., 6: $565-575$ DOI: 10.3844/ajassp.2009.565.575
Affeldt, E.E., J. Hummer and L. Cerdan de la Cruz, 2003. Modeling of Deformation during TMFLoading. In: Thermomechanical Fatigue Behavior of Materials, McGraw, M.A., S. Kalluri, J. Bressers and S.D. Peteves (Eds.). ASTM International, West Conshohocken PA., ISBN: 0803134673, pp: 15-30.

Bill, R.C., M.J. Verrilli, M.A. McGraw and G.R. Halford, 1984. A Preliminary study of the thermo-mechanical fatigue of polycrystalline MAR M-200. Defence Technical Information Centre. http://oai.dtic.mil/oai/oai?verb=getRecord\&metada taPrefix $=$ html\&identifier $=$ ADA 138737

Bodner, S.R., I. Partom and Y. Partom, 1979. Uniaxial cyclic loading of elastic-viscoplastic materials. J. Applied Mech., 46: 805-810. DOI: 10.1115/1.3424658

Boismier, D.A. and H. Sehitoglu, 1990. Thermomechanical fatigue of Mar-M247: Part 1experiments. J. Eng. Mater. Technol., 112: 68-79. DOI: $10.1115 / 1.2903189$

Christ, H.J., A. Jung, H.J. Maier and R. Teteruk, 2003. Thermomechanical fatigue-damage mechanisms and mechanism-based life prediction methods. Sadhana, 28: 147-165. DOI: 10.1007/BF02717131

De-Andres, A., J. Perez and M. Ortiz, 1999. Elastoplastic finite element analysis of threedimensional fatigue crack growth in aluminum shafts subjected to axial loading. Int. J. Solids Struct., 36: 2231-2258. DOI: 10.1016/S00207683(98)00059-6

Djavanroodi, F., 2008. Creep-fatigue crack growth interaction in nickel base supper alloy. Am. J. Applied Sci., 5: 454-460. DOI: 10.3844/ajassp.2008.454.460

Doner, M., 1976. An analysis of elevated temperature fatigue and creep crack growth. J. Eng. Power, 98: 473-479. DOI: 10.1115/1.3446221.

Gaiera, C. And H. Dannbauera, 2003. Fatigue analysis of multiaxially loaded components with the FEpostprocessor FEMFAT-MAX. Eur. Struct. Integr. Soc., 31: 223-240. DOI: 10.1016/S15661369(03)80013-4

Gao, M., R.O. Ritchie and R.K. Kumar, 2005. Highcycle fatigue of nickel-based superalloy ME3 at ambient and elevated temperatures: Role of grainboundary engineering. Metallurg. Mater. Trans. A, 36: 3325-3333. DOI: 10.1007/s11661-005-0007-5

Gao, J.S., K.M. Stolken and R.O. Ritchie, 2007. Highcycle fatigue of nickel-base superalloy René 104 (ME3): Interaction of microstructurally small cracks with grain boundaries of known character. Acta Materialia, 55: 3155-3167. DOI: 10.1016/j.actamat.2007.01.033 
Gocmez, T., A. Awarke and S. Pishinger, 2010. A new low cycle fatigue criterion for the isothermal and out-of-phase thermomechanical loading. Int. J. Fatigue, $\quad 32$ : 769-779. $\quad$ DOI: 10.1016/j.ijfatigue.2009.11.003

Halford, G.R., M.A. McGraw, R.C. Bill and P.D. Fanti, 1988. Bithermal Fatigue: A Link Between Isothermal and Thermomechanical Fatigue. In: Low Cycle Fatigue, Solomon, H.D., G.R. Halford, L.R. Kaisland and B.N. Leis (Eds.). ASTM Intl., Baltimore, ISBN: 080310944X, pp: 625-637.

Halford, G.R., S. Manson, B. Prillhofer, G. Winter and W. Eichlseder, 1976. Life Prediction of ThermalMechanical Fatigue Using Strain Range Partitioning. In: Thermal Fatigue of Materials and Components, Spera, D.A. and D.F. Mowbray (Eds.). ASTM Intl., Baltimore, ISBN: 0-80310586-X, pp: 239-254.

Kang, H.T., Y.L. Lee, J. Chen and D. Fan, 2007. A thermo-mechanical fatigue damage model for variable temperature and loading amplitude conditions. Int. J. Fatigue, 29: 1797-1802. DOI: 10.1016/j.jpfatigue.2007.03.008

Kocabicak, U. and M. Firat, 2004. A simple approach for multiaxial fatigue damage prediction based on FEM post-processing. Mater. Des., 25: 73-82. DOI: 10.1016/S0261-3069(03)00157-2

Lawson, L., M.E. Fine and D. Jeannotte, 1991. Thermomechanical fatigue of a lead alloy Metallurg. Mater. Trans. A, 22: 1059-1070. DOI: 10.1007/BF02661099

Lei, Y., 2008. Finite element crack closure analysis of a compact tension specimen. Int. J. Fatigue, 30: 21-31. DOI:10.1016/j.ijfatigue.2007.02.012.

Lemaitre, J. and J.L. Chaboche, 1990. Mechanics of Solid Materials. 1st Edn., Cambridge University Press, Cambridge, ISBN: 0521328535, pp: 584.

Neu, R.W. and H. Sehitoglu, 1989a. Thermomechanical fatigue, oxidation and creep: Part 1experiments. Met. Trans. A, 20: 1755-1767. DOI: 10.1007/BF02663207

Neu, R.W. and H. Sehitoglu, 1989b. Thermomechanical fatigue, oxidation and creep: Part 2-life prediction. Met. Trans. A, 20: 1769-1783. DOI: 10.1007/BF02663208

Newman, J., 1984. A crack opening stress equation for fatigue crack growth. Int. J. Fracture, 24: 131-135. DOI: 10.1007/BF00020751

Rahman, M.M., A.B. Rosli, M.M. Noor, M.S.M. Sani and J.M. Julie, 2009a. Effects of spot diameter and sheets thickness on fatigue life of spot welded structure based on FEA approach. Am. J. Applied Sci., $\quad$ 6: $137-142 . \quad$ DOI: 10.3844/ajassp.2009.137.142
Rahman, M.M., A.K. Ariffin, S. Abdullah, M.M. Noor and R.A. Bakar et al., 2009b. Assessment of surface treatment on fatigue life of cylinder block for linear engine using frequency response approach. Am. J. Applied Sci., 6: 715-725. DOI: 10.3844/ajassp.2009.715.725

Rees, D.W.A. and B.F. Dyson, 1986. Deformation and fracture behavior under combined creep and fatigue. Int. J. Plasticity, 2: 1-19. DOI: 10.1016/0749-6419(86)90013-6

Sehitoglu, H. And D.A. Boismier, 1990. Thermomechanical fatigue of Mar-M247: Part 2-life prediction. J. Eng. Mat. Tech., 112: 80-89. DOI: 10.1115/1.2903191

Sehitoglu, H., 1992. Thermo-Mechanical Fatigue Life Prediction Methods. In: Advances in Fatigue Lifetime Predictive Techniques, Mitchell M.R. and R.W. Landgraf (Eds.). ASTM Intl., USA., ISBN: 0803114230, pp: 47-76.

Skelton, R.P., 1991. Energy criteria for high temperature low cycle fatigue. Mater Sci. Technol., 7: 427-439.

Skelton, R.P., 1993. Cyclic hardening, softening and crack growth during high temperature fatigue. Mater Sci. Technol., 7: 427-440.

Sun, G.Q. and D.G. Shang, 2010. Prediction of fatigue lifetime under multiaxial cyclic loading using finite element analysis. Mater. Des., 31: 126-133. DOI:10.1016/j.matdes.2009.06.046

Swanson, G.A., I. Linask, D.M. Nissley, P.P. Norris and T.G. Meyer et al., 1986. Life prediction and constitutive models for engine hot section. NASA.

Thomas, G., J. Bressers and D. Raynor, 1982. LowCycle Fatigue and Life Prediction Methods. In: High Temperature Alloys for Gas Turbines, Brunetaud, R. (Ed.). D. Riedel Publishing Co., Netherlands, pp: 291-317.

Velay, V., G. Bernhart and L. Penazzi, 2006. Cyclic behavior modeling of a tempered martensitic hot work tool steel. Int. J. Plasticity, 22: 459-496. DOI: 10.1016/j.ijplas.2005.03.007

Zhuang, W.Z. and N.S. Swansson, 1998. Thermomechanical fatigue life prediction: A critical review. DSTO Aeronautical and Maritime Research Laboratory. http://dspace.dsto.defence.gov.au/dspace/bitstream/ 1947/3887/1/DSTO-TR-0609\%20PR.pdf 